\title{
Molecular signature of selective microRNAs in Cyprinus carpio (Linnaeus 1758):a computational approach
}

\author{
Soumendu Ghosh ${ }^{1 \dagger}$, Manojit Bhattacharya ${ }^{2 \dagger}$, Avijit Karr ${ }^{1}$, Basanta Kumar Das ${ }^{2}$ and Bidhan Chandra Patra ${ }^{1 *}$
}

\begin{abstract}
MicroRNAs (miRNAs) are small single stranded non-coding RNAs that performed significant role in post-transcriptional regulation of target gene product. They are typically conserved among the organisms and also involved in multiple biological processes by degrading the targeted mRNAs by suppression or destabilization. Their conserved nature in various organisms provide a good source of miRNA identification and characterization using comparative genomic approaches through the bio-computational tools. The present work highlighted about common carp's (Cyprinus carpio) conserved miRNAs which were identified and characterized using some bioinformatical strategies based on miRBase, Expressed Sequence Tag (EST) and Genomic Survey Sequence (GSS) databases. Using web based tools total 10 selected miRNAs belongs to 10 different families were illustrated and functionally categorized in Cyprinus carpio. Which have elemental role in regulation and expression of gene-protein interaction specially focused in biological processes of carp. Through real time application of mature miRNA sequences as probe the effective targets for selected common carp miRNAs were detected and catagorised using local BLAST online program and miRBase software. Imperative miRNAs of Cyprinus carpio are indentified via miRBase database and cautiously characterized with the associated gene encoded target protein. Those proteins having a key regulatory role in cellular signal transduction, transcription factor and associated biomolecules responsible for the metabolism, growth and development of carp skeletal muscle as well as preconditioning of skeletal myoblasts components. These selected miRNAs and their targets in common carp may enhance the better understanding and knowhow of miRNAs as superior role in regulating the metabolism, growth and developmental factors of Cyprinus carpio.
\end{abstract}

Keywords: MicroRNA, Cyprinus carpio, Target protein, Gene function

\section{Introduction}

The common carp (Cyprinus carpio, Linnaeus 1758) is an important captured and cultured finfish species in the wider domain of freshwater aquaculture. It is native to Europe and Asian continent and has been introduced to every part of the world except the poles [1-3]. The main attention of the venture is to give a condensed data identified along with the selective miRNAs and their predefined gene target functions in Cyprinus carpio. Precise supportive data concerned with the ribonucleotide-proteins

\footnotetext{
* Correspondence: patrabidhan1962@gmail.com

†Soumendu Ghosh and Manojit Bhattacharya contributed equally to this work.

${ }^{1}$ Centre For Aquaculture Research, Extension \& Livelihood, Department of Aquaculture Management \& Technology, Vidyasagar University, Midnapore, West Bengal 721102, India

Full list of author information is available at the end of the article
}

communication will support the modern, auxiliary science using present day in backing to the real field application on computational methodologies [4]. Researcher already found as the reliable sub- cellular components miRNAs in numerous protein regulatory pathways within the cytoplasmic space; precisely MicroRNAs (miRNAs) are small (20-22 nucleotides/nts) non-coding RNAs, involved primarily in post-transcriptional regulation of mRNA (messenger RNA) when loaded onto RNA-Induced Silencing Complex (RISC). Subsequently the mature miRNAs guided the RISC to specific protein coding messenger RNA (mRNA) target modules, where a very important protein family which is known as Argonaut protein (Ago2) collaborates with mRNA and it involves the function of mRNA repression or destabilization [5, 6]. Recently number of molecular approaches figure out that the biogenesis and function of

(c) The Author(s). 2019 Open Access This article is distributed under the terms of the Creative Commons Attribution 4.0 International License (http://creativecommons.org/licenses/by/4.0/), which permits unrestricted use, distribution, and 
miRNAs are categorically related to the molecular mechanisms or actions of various clinical diseases. Which are potentially regulates many aspect of cellular and sub-cellular activities that might be included animal organ developmental stages, growth, metabolism as well as signal transduction pathways. After distinguishing the evidence and depiction of selective miRNAs family, one of the key fundamental points is to recognize and in-depth analysis of the miRNA target-function qualities based on computational tools. Computational predictions have been widely applied to miRNA target identification connected to the gene-protein network function [7-10]. Knowledge of such gene regulation by selective regulatory miRNA provides direct or indirect mode of action along with it also played a significant role for developing new techniques to support the disease control of fishes [11]. There are several momentous advantages of identifying the functional miRNAs, because it is accurate, appropriate, fast, and inexpensive compared to the others laboratory experimental method in fisheries biology [12-14].

Common carp (Cyprinus carpio) considered as vulnerable to extinction by the IUCN status, it has been intensively studied in terms of its physiology, development and disease resistance compassionate by gene-protein interaction network pathways. In addition, it is also considered as an alternative, persistent vertebrate fish model to zebrafish (Danio rerio) $[15,16]$.

Keeping in view to such particular cases a vital drive has been made for profound analysis and research centered on the miRNAs roles and regulation for gene-target function pathways specified focus to Common carp (Cyprinus carpio). Attention only given to the selected group of miRNA, which have a crucial regulatory, expression role in protein mediated signaling pathways.

\section{microRNA biogenesis pathway}

The biogenesis of miRNAs is a very systemize multistep progression that initiate in the nuclear part of the cell, following transcription and continues through the cytoplasmic space where finally the mature miRNA molecule execute its main function [17, 18]. In nucleus, pri-miRNA are cleaved and released its hairpin like structure precursor component miRNAs (pre-miRNAs) by the coordination with the microprocessor complex which is mainly consists of the RNase-III like enzyme, Drosha component and its other cofactors like DGCR8 [5]. Subsequently the pre-miRNA is recognized by exportin-5 protein and transports to the cytoplasm for further processing. Exportin-5 is an individual protein from the karyopherin group of nucleocytoplasmic transportation factors that rely upon their cofactor viz. Ran protein for their catalytic activities [19, 20]. Within the cytoplasm, pre-miRNAs are subsequently processed into $\sim 22$ nts long miRNA duplexes by the cytoplasmic RNase-III like enzyme, Dicer and its cofactors processed with its catalytic partner Trans-activator RNA (tar)binding protein (TRBP) [19] or PKR-activating protein (PACT) [5, 21]. As consequently, one strand of the duplex compound is joined to the RISC (RNA-induced silencing complex) and serves as an active mature miRNA. After that, the other strand also called the passenger strand of miRNA which is quickly degraded or occasionally loaded into the RISC as a functional miRNA component [5]. RISC is the cytoplasmic effector unit of the miRNA pathway and contains a solitary stranded miRNA directing towards lead objective mRNAs [19]. In this pathway argonaute protein family plays a very imperative role. Argonaute protein (AGO2) mediates RISC effects on mRNA targets directly and mainly involved in the repression or destabilization of mRNA [5, 6] (Fig. 1).

\section{Computational methods Identification of selective miRNA}

The selected miRNA sequences of Cyprinus carpio were acquired from miRbase database (http://miRbase.org). On the other side the EST and GSS sequences of Cyprinus carpio were downloaded from NCBI database (http://www.ncbi.nlm.nih.gov). One miRNA viz. ccr-miR-6732 was identified in the EST database and 5 miRNAs family viz. ccr-miR-430a, ccr-miR-430b, ccr-miR-430c-3p, ccr-miR-365 and ccr-miR-2783 were collected in the GSS database, where rest 4 miRNA i.e. ccr-miR-1, ccr-miR-133, ccr-miR-206, ccr-miR-21 were repossess from the miRBase database [22-26]. The lengths of the identified mature miRNAs typically varied from 20-24 nts. All the collected Cyprinus carpio miRNA sequence considered and compiled as valid candidate after satisfying the basic formula of biogenesis and expression of the miRNAs.

\section{$(\Delta G)$ value calculation of reference miRNA sets}

The $\Delta \mathrm{G}$ value of selected miRNA sequences were calculated by the online program based server of OLIGO NUCLEOTIDE PROPERTIES CALCULATOR [27, 28]. Experimental evidences suggested that, higher $\Delta G$ value containing miRNA having the maximum boding force during the interaction with target mRNA sequences and low chances of loop formation. FASTA format of miRNA base sequences are used for the calculation of $\Delta \mathrm{G}$ value. All the calculated $\Delta \mathrm{G}$ values ranges between 22.9 to $29.4 \mathrm{kcal} / \mathrm{mol}$ (Table 1 ).

\section{Minimum free energy calculation}

Calculation of minimum free energy of selected miRNA sequences by the help of mfold Web Server [28]. It is a supportive tool for nucleic acid folding and hybridization 


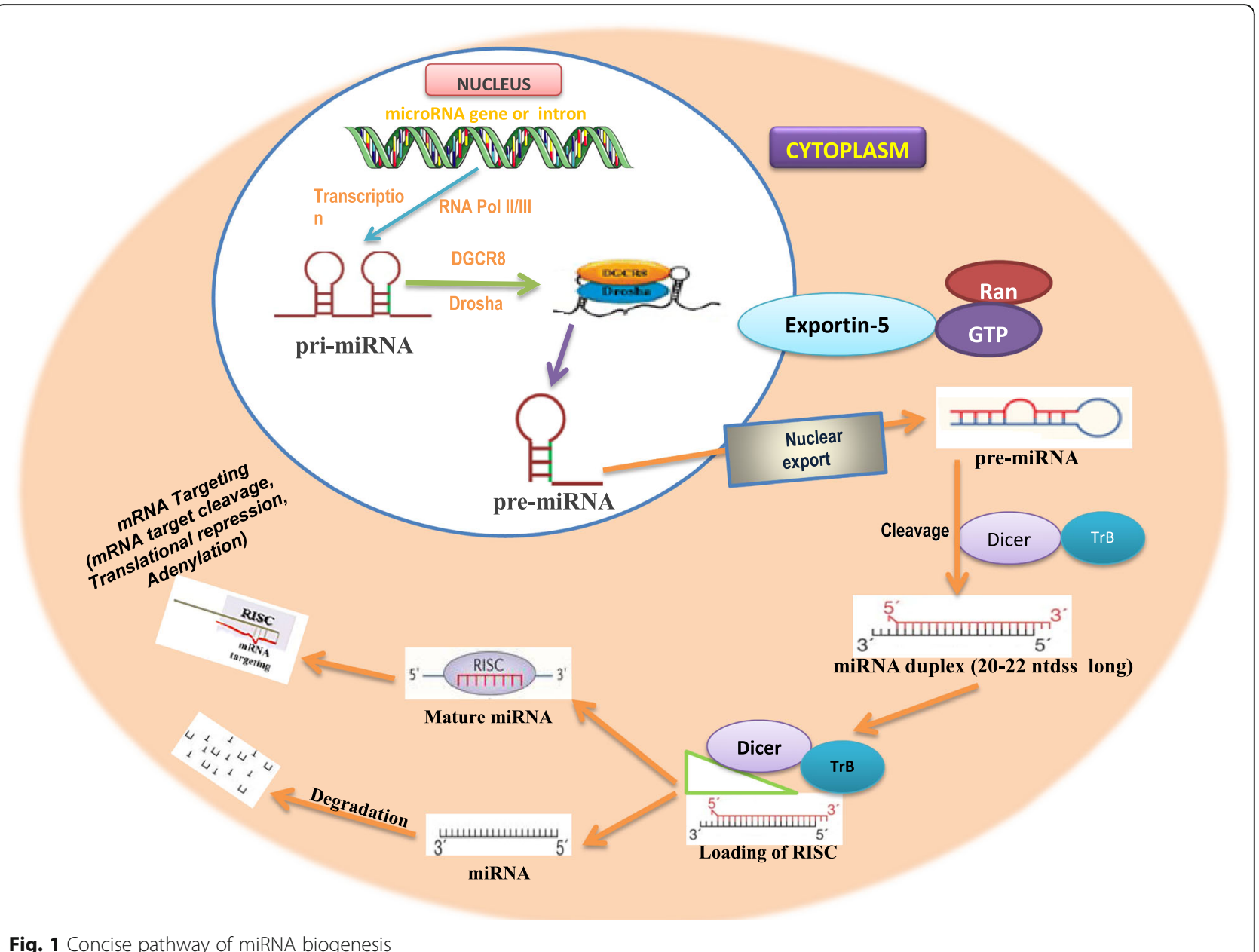

Fig. 1 Concise pathway of miRNA biogenesis

prediction. The folding temperature is fixed at $37^{\circ} \mathrm{C}$ but the temperature varies from a certain range. Here, at first FASTA format sequence placed and result given the value of minimum free energy [29]. In common carp the recognized miRNAs nucleotides mfe values were calculated, those ranges in between - 4.5 to $1.5 \mathrm{kcal} / \mathrm{mol}$ (Table 1 ).

\section{Target gene depiction}

miRNA mainly involved in the diverse range of biological processes such as posttranscriptional regulation of targeted genes. In such case miRNA binds to the target mRNA that are typically located at the $3^{\prime}-$ UTRs part leading to the transcriptional repression or transcript degradation [30]. Total 10 number target gene

Table 1 Cyprinus carpio miRNA characterization

\begin{tabular}{lllll}
\hline SI. no. & miRNAs Name & Mature sequence (5/-3/) & Mfe value (kcal/mol) & AG value (kcal/mol) \\
\hline 1 & ccr-miR-6732 & CAGAAGGUGGAGGCUGGCC & -2.70 & 29.4 \\
2 & ccr-miR-430a & UAAGUGCUAUUUGUUGGGGUAG & -0.70 & 26.1 \\
3 & ccr-miR-430b & AAAGUGCUAUCAAGUUGGGGUAA & -0.50 & 27.9 \\
4 & ccr-miR-430c-3p & UAAGUGCUUCUCUUUGGGGUAG & -4.50 & 27.1 \\
5 & ccr-miR-365 & AAACUUUUGGGGCAGAUUA & -0.10 & 24.1 \\
6 & ccr-miR-2783 & UAAUCGAGGGUGUGGUGUGGGA & 1.40 & 32.2 \\
7 & ccr-miR-1 & UGGAAUGUAAAGAAGUAUGUAU & 0.80 & 22.9 \\
8 & ccr-miR-133 & AGCUGGUAAAAUGGAACCAAA & -2.90 & 25.2 \\
9 & ccr-miR-206 & UGGAAUGUAAGGAAGUGUGUGG & 1.50 & 27.2 \\
\hline 10 & ccr-miR-21 & AGCUUAUCAGACUGGUGUUGGC & -2.00 & 29.2 \\
\hline
\end{tabular}


sites are predicted in Cyprinus carpio. (Table 2) Many experimental and computational approaches have documented that most of the miRNAs largely effects to target transcription factors, signal transduction factors and development [22]. Cyprinus carpio target gene characterizes by the collection of online data sources of NCBI webpage hosted a number of bioinformatics tools and services like EST, GSS along with an archive of microRNA sequences and annotations called miRBase Databases [31-33].

\section{Impact on different gene targets regulated by microRNAs in Cyprinus carpio}

miRNA have a broad variety of gene coded expression patterns in different protein targets of Cyprinus carpio. A descriptive depiction of all selected miRNAs involved in the various gene regulatory functions of Cyprinus carpio has been summarized in the Table 2. The real time miRNA expression in different gene targets is not only limited to specific function but also regulates many other genes in Cyprinus carpio. miRNA expression pattern suggests that the selected miRNAs have a distinct role in signal transduction, metabolism, development as well as growth of skeletal muscle in carp (Fig. 2).

\section{miRNA associated with signal transduction}

Signal transduction mainly controlled by Toll-like receptor 2 and G-protein coupled receptor kinase protein component. Specifically, ccr-miR-6732 and ccr-miR-430a involved in this process within carp. Toll-like Receptors (TLRs) are intimately related type I transmembrane proteins, which form the major Pattern Recognition Receptors (PRRs) to transducer the signals in response to microbial intruders such as bacteria, fungi, protozoa and virus [34, 35]. TLRs are evolutionary conserved sensors of pathogen associated molecular patterns. They identify microbes and activate the signaling pathways, initiation of immune system and inflammatory responses to result in removal of the invading pathogen [36]. This primary immune resistance against foreign and hazardous material is also critical for mounting the appropriate acquired immune responses [37]. However, extreme activation of these pathways may also disturb immune homeostasis leading to some disease such as autoimmune disease, chronic inflammatory diseases etc. Most of the endogenous TLR ligands are produced as danger signals during tissue injury and inflammation [38]. Various methods are liable for the regulation of the TLR-signaling pathways. These include conformational changes, phosphorylation, physical interactions, ubiquitylation and proteasome-mediated degradation involving different regulatory molecules [39, 40]. Among the several regulatory molecules some selected miRNA involved in fine-tuning of the TLR-signaling pathways [41-47] and thus influence host innate defenses against the microbial pathogens [48]. miR-6732 act as an important TLR-activated transcription factors in Common carp (Cyprinus carpio). It can sense the presence of pathogen derived nucleic acid not at the cell surface, but rather within the endosomal compartment of the cell. $\mathrm{CD} 11 \mathrm{~b}$ glycoprotein function as a negative regulator of the TLR signal pathway by engaging in direct crosstalk with the TLR cellular signaling pathway [37].TLR signaling is a tightly regulated process that mainly involve in posttranscriptional regulation. Parallel findings revealed that miRNA associated with positive and negative regulators of TLR signaling which may provide attractive therapeutic targets in infection and inflammation in fish biological process. G-protein couple receptor kinase constitutes a large protein family receptors, that detect molecule outside of the cell and activate internal signal transduction pathways which may cause the ultimately cellular responses occur $[49,50]$. Another miRNA family ccr-miR-430a operates via G-protein pathway. This pathway form a gene encoded protein network that regulates the selected activities of metabolic enzymes, ion channels, transporters and associate to controlling a

Table 2 Cyprinus carpio Target Gene Prediction

\begin{tabular}{|c|c|c|c|c|c|}
\hline SI. no. & miRNAs Name & Gene source & Targeted protein & Target function & References \\
\hline 1 & ccr-miR-6732 & JZ508372(EST) & Toll-like receptor 2 & Signal transduction & [22] \\
\hline 2 & ccr-miR-430a & HR561547(GSS) & G protein-coupled receptor kinase & Signal transduction & \\
\hline 3 & ccr-miR-430b & HN151353(GSS) & $\mathrm{Na}+$ /glucose co transporter & Metabolism & \\
\hline 4 & $c c r-m i R-430 c-3 p$ & HR561547(GSS) & TNF $-a$ & Transcription factor & \\
\hline 5 & ccr-miR-365 & HR561450(GSS) & Rhesus blood group-associated glycoprotein- C & Development & \\
\hline 6 & ccr-miR-2783 & HR551227(GSS) & Matrix metalloproteinase 2 & Metabolism & \\
\hline 7 & ccr-miR-1 & MI0023302 (miRBase) & \multirow[t]{3}{*}{ Multiple muscle-development-related genes } & \multirow{3}{*}{$\begin{array}{l}\text { Play a role in the development } \\
\text { of carp skeletal muscle. }\end{array}$} & \multirow[t]{3}{*}{ [25] } \\
\hline 8 & ccr-miR-133 & MI0023321 (miRBase) & & & \\
\hline 9 & ccr-miR-206 & MI0023366 (miRBase) & & & \\
\hline 10 & ccr-miR-21 & MI0023368 (miRBase) & IL-11/Stat3 anti-apoptotic signalling pathway & Preconditioning of skeletal myoblasts & [25] \\
\hline
\end{tabular}




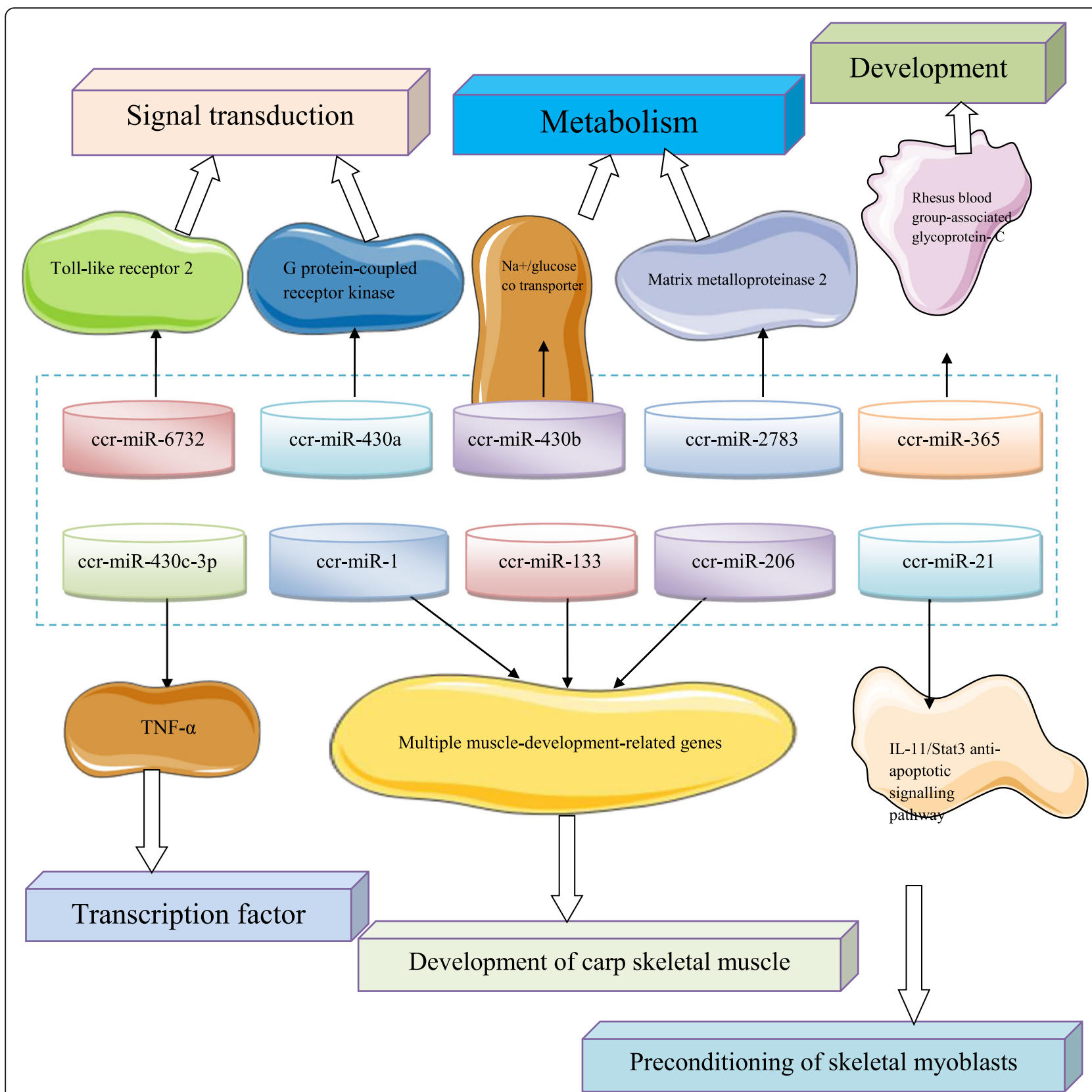

Fig. 2 miRNA regulates different target proteins and multiple functions in Cyprinus carpio

broad ranges of cellular processes which work together within the transcription, motility, contractility and secretary functions of the cells. These cellular processes also monitored many systemic functions in fish body such as embryonic development, gonadal development etc. [51]. On the other hand miR-430a also controls the inflammation in fish body but inappropriate or prolonged inflammation is the chief reason of many diseases, for this purpose it is important to understand the physiological mechanisms that terminate inflammation in-vivo [52].
miRNA related to metabolism

ccr-miR-430b and ccr-miR-2783 plays a crucial role as key metabolic regulators in Cyprinus carpio. These two miRNAs mainly regulates Sodium-dependent Glucose co-transporter (SGLT) in common carp. SGLT are a family of glucose transporter found in the intestinal mucosa of the small intestine and proximal tubule of the nephron [53]. They contribute to renal glucose absorption [53]. SGLT molecules accumulating glucose components from intestinal part or kidney epithelial cells in against to the adverse concentration gradient and 
balancing the superior adjustment of metabolism pathways [54]. Now the SGLT are saturated with the filtered glucose and glucose is never secreted by a healthy nephron [55].

miRNA associated with muscle development of carp Muscle development is controlled by evolutionary conserved gene expression networks of transcription factors that categorize the expression of gene-protein interaction involved in regulating muscle growth and differentiation $[8,56]$. These particular translation factors are controlled by the outflow of miRNAs, working as "on-off" switches [57]. In Cyprinus carpio, a set of miRNAs i.e. ccr-miR-1, ccr-miR-133, ccr-miR-206 and ccr-miR-2783 play significant roles in skeletal muscle development. These muscle specific and highly expressed miRNAs mainly regulates multiple muscle-developmentrelated genes and rhesus blood group-associated glycoprotein-C [58]. In short, miR-1, miR-133 and miR206 mainly expressed in heart, skeletal muscle, gut, eye and skin [25]. Myogenesis is a very complex but precisely regulated developmental process and it mainly associated with the multiple muscle-development-related genes whose mal-regulation can cause many muscular dysfunction diseases in carp [59]. The negative mfe value of ccr-miR-133 and ccr-miR-365 strongly suggested that they actively figure out the gene expression patterns in the muscle tissue in Cyprinus carpio and also controls sarcomeric actin protein organization $[60,61]$.

\section{miRNA involved in preconditioning of skeletal myoblasts}

In Cyprinus carpio preconditioning of skeletal myoblasts is controlled by ccr-miR-21 miRNA. It is ubiquitous small RNA which is vigorously involved in cellular responsiveness to different stimuli $[62,63]$. miR-21 in skeletal myoblasts (MY) preconditioning via interleukin11 (IL-11) induced extracellular signal regulated kinase $1 / 2$ (Erk1/2)-signal transducers and activators of transcription-3 (Stat3) signaling [26]. On the other side, Erk1/2 phosphorylated Stat3 to promote its transcriptional activity [64]. The anti-apoptotic action of miR-21 also linked with multiple transcription factors including signal transducers and Stat3 [64]. IL-11 is a non-glycosylated protein secreted by various cells together with bone marrow stromal cells and its activity related to the cell proliferation $[65,66]$. Whereas the negative mfe value of miR-21 gives the complete knowledge about the key role of preconditioning-induced ccr-miR-21 family in protection of myoblasts (MY) via activation of Erk $1 / 2$ and Stat3 signaling pathway. So, preconditioning of stem and progenitor cells by miRs can be exploited to progress therapeutic effectiveness in the clinical settings in the field of fish biology [25].

\section{miRNA acts as transcription factor}

TNF- $\alpha$ found in several fish species, including the common carp (Cyprinus carpio) [67-71]. ccr-miR-430c-3p regulates TNF- $\alpha$ and function as the transcription factor. In Cyprinus carpio TNF- $\alpha$ primes but does not directly trigger phagocytes and thereby promotes phagocyte activation indirectly via stimulation of endothelial cells [72]. It also regulates host-pathogen interactions and is necessary for protective immunity against intracellular bacteria and fungi but also aligned with intracellular and extracellular protozoan parasites [73, 74]. Here also, membrane bound TNF- $\alpha$ participate in several biological activities as well as control the microbial infection [75-77]. At present, most of the carp are infected by Trypanosoma borreli and leads to increased mortality in Cyprinus carpio [78-80]. It is mainly due to the inhibition of TNF- $\alpha$ gene expression and moreover, used an inhibitor of TNF- $\alpha$ converting enzyme (TACE) to figure out the contribution of mTNF- $\alpha$ to the clearance of parasite within few days in infected carp [72].

\section{Future perspective}

The computational approaches for identifying selected miRNAs and their specific target performed crucial role in consideration of gene regulation at post-transcriptional level of Cyprinus carpio. Such findings will be wonderfully helpful to reveal and find out the importance of gene-protein regulation for developing new techniques towards disease control along with the contemporary drug delivery system. Moreover, modern gene silencing technology will be supportive for somatic development of fishes. Dysregulation of miRNAs may alter the gene protein interaction networks in case of several diseases, like metabolic abnormalities, neurodegenerative disorder etc.; in complementary the miRNA therapy could might be restore the gene expression within the cells to reverse back into normal cellular functioning state. Besides that, their improper function may be the prime object for improvement of potential remedial, which focus for treating different syndromes. Moreover, a single, short miRNA can object single or multiple mRNA gene targets within a cell. Although, difficulty of miRNA-mRNA interactions, accurate detection methodologies and numerous technical difficulties has been arises especially in-vivo system. There are such a large number of favorable circumstances of miRNAs as restorative perspective; for example, miRNAs are little size nucleotide contains a known grouping which is regularly saved among species, an attractive feature from a drug improvement perspective. It indicates that the target relationships between miRNAs and mRNAs and their ultimate effect in fishes are very broad and valuable. The use of miRNA as the future targeted therapy is too bright, promising and spontaneous at current scenario. However, 
with rapidly growing number of miRNA discoveries since more than last 10 years, is definitely encouraging and hopeful. Therefore, more scientific studies are needed in this direction to understand the each and every step of miRNA-controlled protein-gene network pathway. Even though, Cyprinus carpio miRNAs identified and characterized in this research work will definitely provide new opportunities for future genome research in common carp and other fish species. This finding will definitely provide useful, significant information to the researchers and can play an important role in bridging the research gap between aquaculturist and bioinformatics.

\begin{abstract}
Abbreviations
$\triangle \mathrm{G}$ : Delta G; Ago2: Argonaut protein; BLAST: Basic local alignment search tool; ccr: Cyprinus carpio; CD11b: Cluster of differentiation molecule 11B; DGCR8: Digeorge syndrome chromosomal [OR CRITICAL] region 8; Erk-1/ 2: Extracellular signal regulated kinase 1/2; EST: Expressed sequence tag GPCRs: G protein-coupled receptors; GSS: Genome survey sequences; IL11: Interleukin-11; IUCN: International union for conservation of nature; kcal/ mol: Kilocalories/Mole; mfe: Minimum folding free energies; mfold: Minimum energy fold; miRBase: Micro RNA base registry; MiRNA: Micro RNA; mRNA: Messenger RNA; mTNF-a: Membrane bound TNF-a; MY: Myoblasts; NCBI: National center for biotechnology information; nt:: Nucleotide; PACT: PKR-activating protein; pre-miRNAs: Precursor micro RNA; primiRNA: Primary micro RNA; PRRs: Pattern recognition receptors; Ran : Rasrelated nuclear protein; RISC: RNA-induced silencing complex; RNase III: Ribonuclease III; SGLT: Sodium-dependent glucose co-transporter; STAT3 : Signal transducer and activator of transcription 3; TACE: TNF-a converting enzyme; TLRs: Toll-like receptors; TNF-a: Tumor necrosis factor a; TRBP: Transactivator RNA (TAR)-binding protein; UTR: Untranslated region
\end{abstract}

\section{Acknowledgements}

The authors would like to thank the Science and Engineering Research Board, Department of Science and Technology, Govt. of India for financial assistance to carry out the research work (Project file No Ref. No. PDF/2016/001776).

\section{Funding}

Not applicable.

\section{Availability of data and materials}

Not applicable.

\section{Authors' contributions}

SG did the analysis and gene function study, MB and AK performed the online study and data design, BCP and BKD wrote the manuscript. All authors read and approved the final manuscript.

\section{Ethics approval and consent to participate}

Not applicable.

\section{Consent for publication}

Not applicable.

\section{Competing interests}

The authors declare that they have no competing interests.

\section{Publisher's Note}

Springer Nature remains neutral with regard to jurisdictional claims in published maps and institutional affiliations.

\section{Author details}

${ }^{1}$ Centre For Aquaculture Research, Extension \& Livelihood, Department of Aquaculture Management \& Technology, Vidyasagar University, Midnapore, West Bengal 721102, India. ${ }^{2}$ ICAR-Central Inland Fisheries Research Institute, Barrackpore, Kolkata, West Bengal 700 120, India.
Received: 19 August 2017 Accepted: 26 February 2019

Published online: 15 March 2019

\section{References}

1. KH A: Synopsis of biological data on common carp/cyprinus carpio, linnaeus, 1758/-Asia and the Far East. Provisional version 1966.

2. Balon EK. Origin and domestication of the wild carp, Cyprinus carpio: from Roman gourmets to the swimming flowers. Aquaculture. 1995;129(1-4):3-48

3. Flajšhans M, Hulata $\mathrm{G}$ : Common carp-Cyprinus carpio. Genetic impact of aquaculture activities on native populations (Editors D Corosetti, E GarciaVasquez \& E Veerspoor) Sixth Framework plan of the EC, final scientific report 2007:32-39.

4. Ajay SS. Novel bioinformatics approaches for microRNA detection and target prediction: University of Michigan; 2009.

5. Bhattacharya M, Sharma AR, Sharma G, Patra BC, Nam J-S, Chakraborty C, Lee S-S. The crucial role and regulations of miRNAs in zebrafish development. Protoplasma. 2017;254(1):17-31.

6. Krol J, Loedige I, Filipowicz W. The widespread regulation of microRNA biogenesis, function and decay. Nat Rev Genet. 2010;11(9):597.

7. Huang Y, Shen XJ, Zou Q, Wang SP, Tang SM, Zhang GZ. Biological functions of microRNAs: a review. J Physiol Biochem. 2011;67(1):129-39.

8. Wienholds E, Kloosterman WP, Miska E, Alvarez-Saavedra E, Berezikov E, de Bruijn E, Horvitz HR, Kauppinen S, Plasterk RH. MicroRNA expression in zebrafish embryonic development. Science. 2005;309(5732):310-1.

9. Bizuayehu TT, Babiak I. MicroRNA in teleost fish. Genome Biol Evol. 2014;6(8):1911-37.

10. Wienholds E, Plasterk RH. MicroRNA function in animal development. FEBS Lett. 2005;579(26):5911-22.

11. Adamek M, Syakuri H, Harris S, Rakus KŁ, Brogden G, Matras M, Irnazarow I, Steinhagen D. Cyprinid herpesvirus 3 infection disrupts the skin barrier of common carp (Cyprinus carpio L.). Vet Microbiol. 2013;162(2):456-70.

12. Hafeez A. MicroRNAs from diagnosis to therapy: future perspective. Transl Biomed. 2016;7(4):1-2.

13. Vlachos IS, Paraskevopoulou MD, Karagkouni D, Georgakilas G, Vergoulis T, Kanellos I, Anastasopoulos I-L, Maniou S, Karathanou K, Kalfakakou D. DIANATarBase v7. 0: indexing more than half a million experimentally supported miRNA: mRNA interactions. Nucleic Acids Res. 2014;43(D1):D153-9.

14. Dong H, Lei J, Ding L, Wen Y, Ju H, Zhang X. MicroRNA: function, detection, and bioanalysis. Chem Rev. 2013;113(8):6207-33.

15. Kozomara A, Griffiths-Jones S. miRBase: annotating high confidence microRNAs using deep sequencing data. Nucleic Acids Res. 2013;42(D1): D68-73.

16. Cossins AR, Crawford DL. Opinion: fish as models for environmental genomics. Nat Rev Genet. 2005;6(4):324.

17. Yang J-S, Lai EC. Alternative miRNA biogenesis pathways and the interpretation of core miRNA pathway mutants. Mol Cell. 2011;43(6):892-903.

18. Kim VN, Han J, Siomi MC. Biogenesis of small RNAs in animals. Nat Rev Mol Cell Biol. 2009:10(2):126-39.

19. Melo CA, Melo SA. MicroRNA biogenesis: dicing assay. RNA Mapping. 2014: 219-26.

20. Murchison EP, Hannon GJ. miRNAs on the move: miRNA biogenesis and the RNAi machinery. Curr Opin Cell Biol. 2004;16(3):223-9.

21. Maurin T, Cazalla D, Yang J-S, Bortolamiol-Becet D, Lai EC. RNase IIIindependent microRNA biogenesis in mammalian cells. Rna. 2012;18(12): 2166-73.

22. Bartel DP. MicroRNAs: target recognition and regulatory functions. cell. 2009; 136(2):215-33

23. Friedman RC, Farh KK-H, Burge CB, Bartel DP. Most mammalian mRNAs are conserved targets of microRNAs. Genome Res. 2009:19(1):92-105.

24. Shibata M, Nakao H, Kiyonari H, Abe T, Aizawa S. MicroRNA-9 regulates neurogenesis in mouse telencephalon by targeting multiple transcription factors. J Neurosci. 2011;31(9):3407-22.

25. Yan $X$, Ding L, Li Y, Zhang X, Liang Y, Sun $X$, Teng C-B. Identification and profiling of microRNAs from skeletal muscle of the common carp. PLoS One. 2012;7(1):e30925.

26. Haider KH, Idris NM, Kim HW, Ahmed RP, Shujia J, Ashraf M. MicroRNA-21 is a key determinant in IL-11/Stat3 anti-apoptotic signalling pathway in preconditioning of skeletal myoblasts. Cardiovasc Res. 2010:88(1):168-78.

27. Chavali S, Mahajan A, Tabassum R, Maiti S, Bharadwaj D. Oligonucleotide properties determination and primer designing: a critical examination of predictions. Bioinformatics. 2005;21(20):3918-25. 
28. Mathews DH, Sabina J, Zuker M, Turner DH. Expanded sequence dependence of thermodynamic parameters improves prediction of RNA secondary structure. J Mol Biol. 1999;288(5):911-40.

29. Zuker M. Mfold web server for nucleic acid folding and hybridization prediction. Nucleic Acids Res. 2003;31(13):3406-15.

30. Ambros V. The functions of animal microRNAs. Nature. 2004:431(7006):350.

31. The Physiological Society: PROCEEDINGS OF THE SCIENTIFIC MEETING HELD AT Newcastle upon Tyne. 1995;482:1-24.

32. Savan R, Sakai M. Analysis of expressed sequence tags (EST) obtained from common carp, Cyprinus carpio L., head kidney cells after stimulation by two mitogens, lipopolysaccharide and concanavalin-a. Comp Biochem Physiol B: Biochem Mol Biol. 2002;131(1):71-82.

33. Griffiths-Jones S, Grocock RJ, Van Dongen S, Bateman A. Enright AJ: miRBase: microRNA sequences, targets and gene nomenclature. Nucleic Acids Res. 2006:34(suppl_1):D140-4.

34. Takeda K, Akira S. Toll-like receptors in innate immunity. Int Immunol. 2005;17(1):1-14

35. Takagi M. Toll-like receptor. J Clin Exp Hematop. 2011;51(2):77-92.

36. Quinn SR, O'neill LA. A trio of microRNAs that control toll-like receptor signalling. Int Immunol. 2011;23(7):421-5.

37. Qian C, Cao X. Regulation of toll-like receptor signaling pathways in innate immune responses. Ann N Y Acad Sci. 2013;1283(1):67-74.

38. Harris HE, Andersson U, Pisetsky DS. HMGB1: a multifunctional alarmin driving autoimmune and inflammatory disease. Nat Rev Rheumatol. 2012;8(4):195-202

39. He X, Jing Z, Cheng G. MicroRNAs: new regulators of toll-like receptor signalling pathways. Biomed Res Int. 2014;2014.

40. O'neill LA. When signaling pathways collide: positive and negative regulation of toll-like receptor signal transduction. Immunity. 2008;29(1):12-20.

41. Li Y, Shi X. MicroRNAs in the regulation of TLR and RIG-I pathways. Cell Mol Immunol. 2013;10(1):65.

42. Olivieri F, Rippo MR, Prattichizzo F, Babini L, Graciotti L, Recchioni R, Procopio AD. Toll like receptor signaling in "inflammaging": microRNA as new players. Immun Ageing. 2013;10(1):11.

43. O'neill LA, Sheedy FJ, McCoy CE. MicroRNAs: the fine-tuners of toll-like receptor signalling. Nat Rev Immunol. 2011;11(3):163.

44. Nahid MA, Satoh M, Chan EK. MicroRNA in TLR signaling and endotoxin tolerance. Cell Mol Immunol. 2011:8(5):388.

45. Ma X, Becker Buscaglia LE, Barker JR, Li Y. MicroRNAs in NF-kB signaling. J Mol Cell Biol. 2011;3(3):159-66.

46. Zhou R, O'hara SP, Chen X-M. MicroRNA regulation of innate immune responses in epithelial cells. Cell Mol Immunol. 2011;8(5):371.

47. Coll RC, O'Neill LA. New insights into the regulation of signalling by toll-like receptors and nod-like receptors. J Innate Immun. 2010;2(5):406-21.

48. Wendlandt EB, Graff JW, Gioannini TL, McCaffrey AP, Wilson ME. The role of microRNAs miR-200b and miR-200c in TLR4 signaling and NF-KB activation. Innate Immun. 2012;18(6):846-55.

49. Ribas C, Penela P, Murga C, Salcedo A, García-Hoz C, Jurado-Pueyo M, Aymerich I, Mayor $F$. The G protein-coupled receptor kinase (GRK) interactome: role of GRKs in GPCR regulation and signaling. Biochimica et Biophysica Acta (BBA)-Biomembranes. 2007;1768(4):913-22.

50. Tuteja N. Signaling through $\mathrm{G}$ protein coupled receptors. Plant Signal Behav. 2009:4(10):942-7.

51. Neves SR, Ram PT, lyengar R. G protein pathways. Science. 2002;296(5573): 1636-9.

52. Ohta A, Sitkovsky M. Role of G-protein-coupled adenosine receptors in downregulation of inflammation and protection from tissue damage. Nature. 2001;414(6866):916-20

53. Wood IS, Trayhurn P. Glucose transporters (GLUT and SGLT): expanded families of sugar transport proteins. Br J Nutr. 2003;89(1):3-9.

54. Nie G-X, Wang B, Yan X, Hou C-X, Zhang J-X, Zhang X-S, Zheng J-L, Wang JL. Expression of sglt1 gene in Cyprinus carpio and preparation of its polyclonal antibody. J Fish China. 2012;3:003.

55. Boyd C. Facts, fantasies and fun in epithelial physiology. Exp Physiol. 2008;93(3):303-14.

56. Braun T, Gautel M. Transcriptional mechanisms regulating skeletal muscle differentiation, growth and homeostasis. Nat Rev Mol Cell Biol. 2011;12(6): 349-61.

57. Flynt AS, Li N, Thatcher EJ, Solnica-Krezel L, Patton JG. Zebrafish miR-214 modulates hedgehog signaling to specify muscle cell fate. Nat Genet. 2007:39(2):259.
58. Huang Y, Ren H-T, Zou Q, Wang Y-Q, Zhang J-L, Yu X-L. Computational identification and characterization of miRNAs and their target genes from five cyprinidae fishes. Saudi J Biol Sci. 2015;24(6):1126-35.

59. Zheng Q, Zhang Y, Chen Y, Yang N, Wang X-J, Zhu D. Systematic identification of genes involved in divergent skeletal muscle growth rates of broiler and layer chickens. BMC Genomics. 2009;10(1):87.

60. Mishima Y, Abreu-Goodger C, Staton AA, Stahlhut C, Shou C, Cheng C, Gerstein M, Enright AJ, Giraldez AJ. Zebrafish miR-1 and miR-133 shape muscle gene expression and regulate sarcomeric actin organization. Genes Dev. 2009;23(5):619-32.

61. Sweetman D, Goljanek K, Rathjen T, Oustanina S, Braun T, Dalmay T, Münsterberg A. Specific requirements of MRFs for the expression of muscle specific microRNAs, miR-1, miR-206 and miR-133. Dev Biol. 2008;321(2):491-9.

62. Krichevsky AM, Gabriely G. miR-21: a small multi-faceted RNA. J Cell Mol Med. 2009;13(1):39-53.

63. Yan L-X, Huang X-F, Shao Q, Huang M-Y, Deng L, Wu Q-L, Zeng Y-X, Shao J$Y$. MicroRNA miR-21 overexpression in human breast cancer is associated with advanced clinical stage, lymph node metastasis and patient poor prognosis. Rna. 2008;14(11):2348-60.

64. Waxman AB, Mahboubi K, Knickelbein RG, Mantell LL, Manzo N, Pober JS, Elias JA. Interleukin-11 and interleukin-6 protect cultured human endothelial cells from H2O2-induced cell death. Am J Respir Cell Mol Biol. 2003;29(4):513-22.

65. Boulton TG, Zhong Z, Wen Z, Darnell JE, Stahl N, Yancopoulos GD. STAT3 activation by cytokines utilizing gp130 and related transducers involves a secondary modification requiring an $\mathrm{H} 7$-sensitive kinase. Proc Natl Acad Sci. 1995;92(15):6915-9.

66. Yang YC, Yin T. Interleukin (IL)-11-mediated Signal Transduction. Ann N Y Acad Sci. 1995;762(1):31-41.

67. Savan R, Sakai M. Presence of multiple isoforms of TNF alpha in carp (Cyprinus carpio L.): genomic and expression analysis. Fish Shellfish Immunol. 2004;17(1):87-94.

68. Zou J, Wang T, Hirono I, Aoki T, Inagawa H, Honda T, Soma G-I, Ototake M, Nakanishi T, Ellis A. Differential expression of two tumor necrosis factor genes in rainbow trout, Oncorhynchus mykiss. Dev Comp Immunol. 2002;26(2):161-72.

69. Savan R, Kono T, Igawa D, Sakai M. A novel tumor necrosis factor (TNF) gene present in tandem with theTNF-a gene on the same chromosome in teleosts. Immunogenetics. 2005:57(1-2):140-50.

70. Haugland $\varnothing$, Mercy IS, Romøren K, Torgersen J, Evensen $\varnothing$. Differential expression profiles and gene structure of two tumor necrosis factor-a variants in Atlantic salmon (Salmo salar L.). Mol Immunol. 2007;44(7):1652-63.

71. Laing KJ, Wang T, Zou J, Holland J, Hong S, Bols N, Hirono I, Aoki T, Secombes CJ. Cloning and expression analysis of rainbow trout Oncorhynchus mykiss tumour necrosis factor-a. FEBS J. 2001;268(5):1315-22.

72. Forlenza M, Magez S, Scharsack JP, Westphal A, Savelkoul HF, Wiegertjes GF. Receptor-mediated and lectin-like activities of carp (Cyprinus carpio) TNF-a. J Immunol. 2009:183(8):5319-32.

73. Pfeffer K. Biological functions of tumor necrosis factor cytokines and their receptors. Cytokine Growth Factor Rev. 2003;14(3):185-91.

74. Clark IA. How TNF was recognized as a key mechanism of disease. Cytokine Growth Factor Rev. 2007:18(3):335-43.

75. Decker T, Lohmann-Matthes M, Gifford G. Cell-associated tumor necrosis factor (TNF) as a killing mechanism of activated cytotoxic macrophages. J Immunol. 1987;138(3):957-62.

76. Fremond C, Allie N, Dambuza I, Grivennikov SI, Yeremeev V, Quesniaux VF Jacobs M, Ryffel B. Membrane TNF confers protection to acute mycobacterial infection. Respir Res. 2005;6(1):136.

77. Allie N, Alexopoulou L, Quesniaux VJ, Fick L, Kranidioti K, Kollias G, Ryffel B, Jacobs M. Protective role of membrane tumour necrosis factor in the host's resistance to mycobacterial infection. Immunology. 2008;125(4):522-34.

78. Scharsack J, Steinhagen D, Kleczka C, Schmidt J, Körting W, Michael R, Leibold W, Schuberth H. The haemoflagellate Trypanoplasma borreli induces the production of nitric oxide, which is associated with modulation of carp (Cyprinus carpio L.) leucocyte functions. Fish Shellfish Immunol. 2003:14(3):207-22

79. Saeij JP, de Vries BJ, Wiegertjes GF. The immune response of carp to Trypanoplasma borreli: kinetics of immune gene expression and polyclonal lymphocyte activation. Dev Comp Immunol. 2003;27(10):859-74.

80. Saeij JP, van Muiswinkel WB, van de Meent M, Amaral C, Wiegertjes GF. Different capacities of carp leukocytes to encounter nitric oxide-mediated stress: a role for the intracellular reduced glutathione pool. Dev Comp Immunol. 2003;27(6):555-68. 